\title{
Stoichiometry Control of ZnO Thin Film by Adjusting Working Gas Ratio during Radio Frequency Magnetron Sputtering
}

\author{
Chaoyang Li, ${ }^{1}$ Dapeng Wang, ${ }^{1}$ Zeming Li, ${ }^{1}$ Xin Li, ${ }^{1}$ Toshiyuki Kawaharamura, ${ }^{1}$ and \\ Mamoru Furuta ${ }^{2}$ \\ ${ }^{1}$ Institute for Nanotechnology, Kochi University of Technology, 185 Miyanokuchi, Tosayamada-cho, Kami, Kochi 782-8502, Japan \\ ${ }^{2}$ Environmental Science and Engineering, Kochi University of Technology, 185 Miyanokuchi, Tosayamada-cho, \\ Kami, Kochi 782-8502, Japan
}

Correspondence should be addressed to Chaoyang Li; li.chaoyang@kochi-tech.ac.jp

Received 15 November 2012; Accepted 8 February 2013

Academic Editor: Sung-Hoon Kim

Copyright (C) 2013 Chaoyang Li et al. This is an open access article distributed under the Creative Commons Attribution License, which permits unrestricted use, distribution, and reproduction in any medium, provided the original work is properly cited.

$\mathrm{ZnO}$ thin films were deposited on quartz glasses by a radio frequency (rf) magnetron sputtering. The mechanism for stoichiometry in the $\mathrm{ZnO}$ thin films was investigated by adjusting $\mathrm{Ar} / \mathrm{O}_{2}$ working gas ratio during deposition. The optical emission spectroscopy (OES) in situ measurement revealed the kinetics species variation during rf plasma deposition process. It was found that the intensity of the excited atomic oxygen $\left(\mathrm{O}^{*}\right)$ was increased with the oxygen ratio increasing, resulting in enhancing the oxidization effect during $\mathrm{ZnO}$ film fabrication. On the contrary, the intensities of atomic zinc emission were gradually decreased, resulting in the zinc ratio in the film were decreased with the oxygen ratio increasing. Therefore, it is possible to control the stoichiometry of $\mathrm{ZnO}$ film by simply adjusting the working gas ambient in the rf plasma deposition. The structural and optical properties of $\mathrm{ZnO}$ thin films were investigated as well.

\section{Introduction}

In recent years zinc oxide $(\mathrm{ZnO})$ thin films, a compound semiconductor material with a wide-band gap of $(3.37 \mathrm{eV}$ at $300 \mathrm{~K})$, have attracted much attention for applying in different photonic and electronic devices such as optical waveguides, thin film transistor, and gas sensors [1-3], due to its promising electrical, optical, and piezoelectric properties. Among the many fabrication techniques of $\mathrm{ZnO}$ film, radio frequency (rf) magnetron sputtering is considered as a convenient method for deposition of homogeneous $\mathrm{ZnO}$ thin film on large area because the stability and reproducibility of $\mathrm{ZnO}$ films are quite high comparing to other techniques [4]. In our previously work $[3,5]$, some optimum deposition conditions using $\mathrm{rf}$ magnetron sputtering system had been found to prepare high-quality ZnO films for TFTs application.

We already found that the bombardment effect of energetic particles during $\mathrm{rf}$ magnetron sputtering was one of the important factors influencing the properties of $\mathrm{ZnO}$ thin films [6]. Comparing to a low-pressure deposition [7], we found that the properties of as-deposited $\mathrm{ZnO}$ thin films were changed by a high-pressure deposition procedure. However, the structural and optical properties of $\mathrm{ZnO}$ films obtained from high-pressure deposition process were still not quite understood. In this research, the effects of different working gas $\left(\mathrm{Ar} / \mathrm{O}_{2}\right)$ ratios on the fabrication of $\mathrm{ZnO}$ films were investigated under a high deposition pressure of $7 \mathrm{~Pa}$. The mechanism for $\mathrm{ZnO}$ film stoichiometry was discussed, and the structural and optical properties of $\mathrm{ZnO}$ films were evaluated. The experiment result is expected to supply helpful information for controlling the quality of as-deposited $\mathrm{ZnO}$ films for future application in the TFT and other optoelectronic devices.

\section{Experimental}

$\mathrm{ZnO}$ films (500 $\mathrm{nm}$ in thickness) were deposited onto quartz glasses by $\mathrm{rf}(13.56 \mathrm{MHz})$ magnetron sputtering system using a 4-inch $\mathrm{ZnO}(5 \mathrm{~N})$ target. The target was located on the cathode $60 \mathrm{~mm}$ away from the substrate stage. Prior to deposition, the substrate on the anode was preheated to $150^{\circ} \mathrm{C}$ 


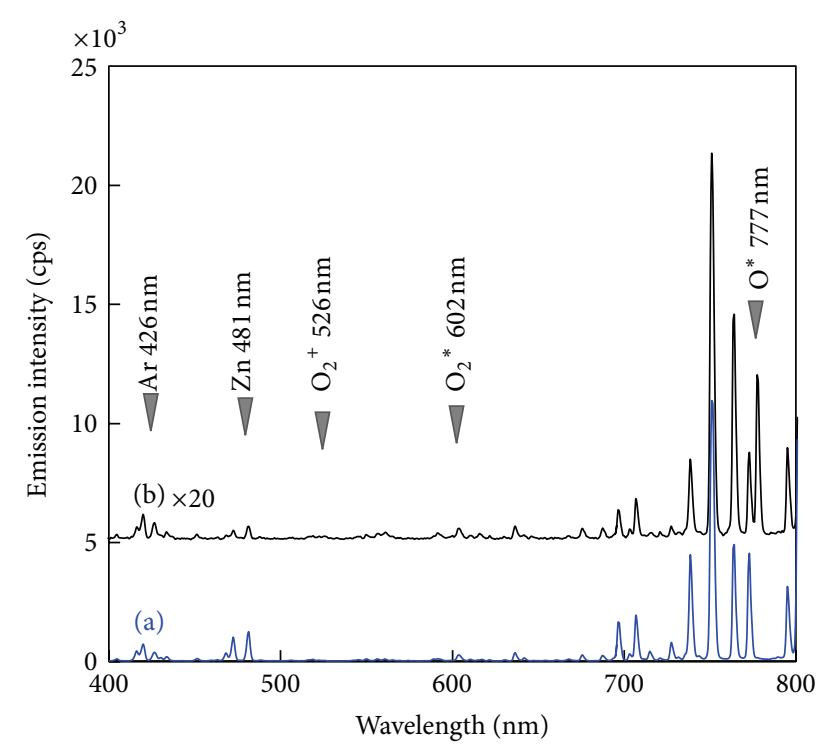

FIgURE 1: (Color online) Typical optical emission spectra obtained from in-situ measurement during $\mathrm{ZnO}$ deposition: (a) Ar: $30 \mathrm{sccm}$ and, (b) $\mathrm{Ar} / \mathrm{O}_{2}=10 / 30(\mathrm{sccm} / \mathrm{sccm})$ at deposition pressure of $7 \mathrm{~Pa}$.

for 1 hour. The working chamber was evacuated to $5 \times 10^{-5} \mathrm{~Pa}$ with a turbo molecular pump. The rf magnetron sputtering deposition process was kept at power of $180 \mathrm{~W}$ for the target, under a deposition pressure of $7 \mathrm{~Pa}$. In order to investigate the effects of working gas ratio $\left(\mathrm{Ar} / \mathrm{O}_{2}\right)$ on the properties of $\mathrm{ZnO}$ films, the working gases were set in different $\mathrm{Ar} / \mathrm{O}_{2}$ $(10 / 5,10 / 10$, and $10 / 30 \mathrm{sccm} / \mathrm{sccm})$ ratio by adjusting the mass flow controllers (MFCs). Additionally, the pure argon and pure oxygen gases depositions were also carried out for comparison during the deposition processes.

During the rf deposition process, a photonic multichannel spectra analyzer (Hamamatsu C-7473) system was used to in situ monitor the optical emission from excited species in the rf plasma. Before the deposition started, the optical fiber directly touched on the outside of quartz window in the chamber, positioned at the middle of cathode and anode. The crystal structure of the $\mathrm{ZnO}$ films was characterized using an X-ray diffraction system (Rigaku ATX-G diffractometer), employing a $\mathrm{Cu} K \alpha$ tube $(\lambda=0.154178 \mathrm{~nm})$ radiation. The surface morphologies of the films were observed by a field emission scanning electron microscope (FE-SEM) system (JEOL-JSM7400F). The different luminescent characteristics of $\mathrm{ZnO}$ films were measured by photoluminescence (PL) measurement, which was performed on an iHR320 Micro$\mathrm{PL} /$ Raman spectroscope (Horiba). An He-Cd laser with a wavelength of $325 \mathrm{~nm}$ at a power of $20 \mathrm{~mW}$ was used as an excitation light source. All of measurements were carried out at room temperature.

\section{Results and Discussion}

Figure 1 shows the OES spectra in situ measurement for the energetic species in the rf plasma during the $\mathrm{ZnO}$ thin films deposited with the different working gases ambient.
The typical emission peaks from different emission particles during the deposition could be detected as argon (426 nm) corresponding to the $5 p-4$ s transition, metal zinc ( $481 \mathrm{~nm}$ ) corresponding to the $4 \mathrm{p}-5 \mathrm{~s}$ transition [8], excited atomic oxygen $\left(\mathrm{O}^{*}\right)(777 \mathrm{~nm})$ corresponding to the $5 \mathrm{p}-5$ s transition, and molecular ion oxygen $\left(\mathrm{O}_{2}{ }^{+}\right)(526 \mathrm{~nm})$ (first negative system) [9], molecular oxygen $\left(\mathrm{O}_{2}{ }^{*}\right)(602 \mathrm{~nm})$ corresponding to transitions from ${ }^{4} \Sigma$-g to ${ }^{4} \Pi_{\mu}[10]$. The OES spectra from the $750 \mathrm{~nm}$ Ar I and $428 \mathrm{~nm}$ Ar II lines was recorded. When the deposition uses only argon as a working gas, ionic species of oxygen present in the rf plasma come entirely from the $\mathrm{ZnO}$ target. It was obviously observed that the intensity of zinc emission was much higher (more than 20 times) in the only argon deposition than that in the $\mathrm{Ar} / \mathrm{O}_{2}(10 / 30 \mathrm{sccm} / \mathrm{sccm})$ deposition.

Figure 2 shows the emission intensities originated from different energetic species: $\mathrm{Ar}(426 \mathrm{~nm}), \mathrm{O}^{*}(777 \mathrm{~nm}), \mathrm{O}_{2}{ }^{+}$ $(526 \mathrm{~nm})$, and $\mathrm{Zn}(481 \mathrm{~nm})$ and emission intensity ratios of $\mathrm{Zn} / \mathrm{O}^{*}$ and $\mathrm{O}^{*} / \mathrm{Ar}$ as function of oxygen concentration. Comparing the emission intensity from different energetic species peaks, it was found that the excited atomic oxygen $\mathrm{O}^{*}$ in the rf plasma was increased with the oxygen ratio increasing. On the contrary, argon, $\mathrm{O}_{2}{ }^{+}$, and metal atomic zinc emission were correspondingly decreased. In Figure 2(b), the dependence of emission intensity ratio of $\mathrm{Zn} / \mathrm{O}^{*}$ and $\mathrm{O}^{*} / \mathrm{Ar}$ as function of oxygen concentration was compared as well. It was found that the $\mathrm{Zn} / \mathrm{O}^{*}$ ratio was decreased with the oxygen increase, which meant that the oxidation effect of metal zinc was suppressed with the oxygen concentration increasing resulting in the zinc ratio in the film stoichiometry decreased with the oxygen ratio increase.

It was reported [11] that the $\mathrm{O}^{*}$ existed in the rf plasma during $\mathrm{Ar} / \mathrm{O}_{2}$ radio frequency sputtering is negative oxygen ion, which contributed to neutralization in plasma on the way to the anode [9] and had major influence on thin film growth. With $\mathrm{O}^{*}$ content increasing, the plasma neutralization will be increased during the film deposition, resulting in deposition rate decrease, which was confirmed by the deposition rate measurement shown in Figure 3 later. In the OES result, the excited atomic oxygen $\mathrm{O}^{*}$ was gradually increased with the oxygen ratio increasing, which contributed to enhancing the oxidation of the $\mathrm{ZnO}$ films, so that the crystallinity of $\mathrm{ZnO}$ film might be improved with oxygen ratio increasing, which could be confirmed by the XRD measurement result later.

As well known, the argon gas contributed to the bombardment effect to the target, it was found that the argon emission was decreased with the oxygen ratio increasing from OES in situ measurement, which led to the deposition rate of $\mathrm{ZnO}$ film being remarkably decreased. In this experiment, the deposition rate was decreased from 13.8, 8.06, 6.66, 5.65 to $5.02 \mathrm{~nm} / \mathrm{min}$, respectively, with oxygen ratio increasing, as shown in Figure 3. Meanwhile, $\mathrm{O}^{*} / \mathrm{Ar}$ was also increased with the oxygen increasing, which meant that the $\mathrm{ZnO}$ oxidization effect was much stronger than argon bombardment effect during the $\mathrm{ZnO}$ film deposition.

Figure 4 shows the morphologies of the obtained $\mathrm{ZnO}$ thin films deposited with different working gas ambient. It was clearly observed that all of the obtained films existed 


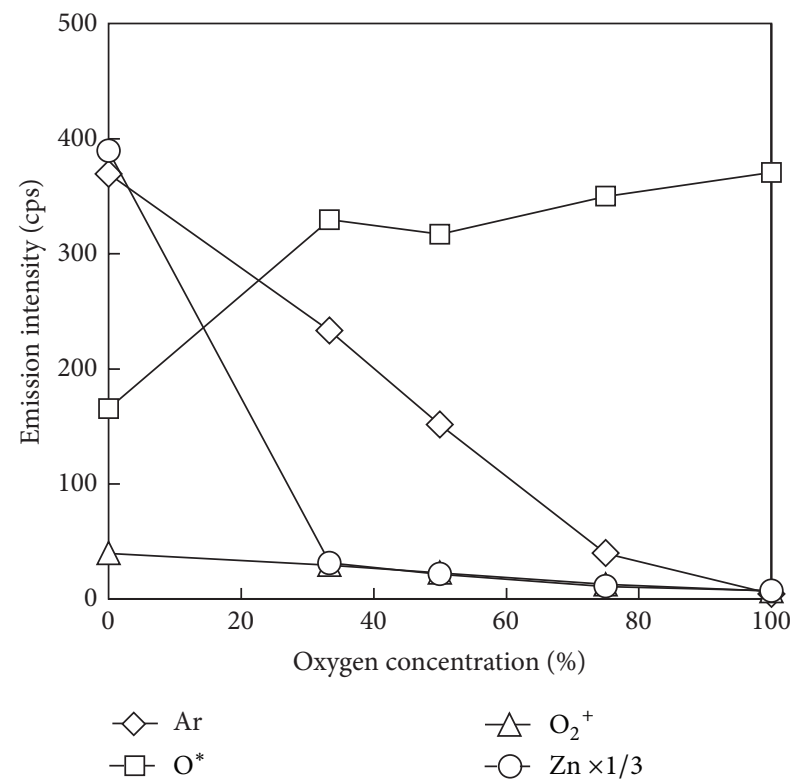

(a)

Figure 2: (a) Emission intensities originated from $\operatorname{Ar}(426 \mathrm{~nm}), \mathrm{O}^{*}$ ratios of $\mathrm{Zn} / \mathrm{O}^{*}$ and $\mathrm{O}^{*} / \mathrm{Ar}$ as function of oxygen concentration.

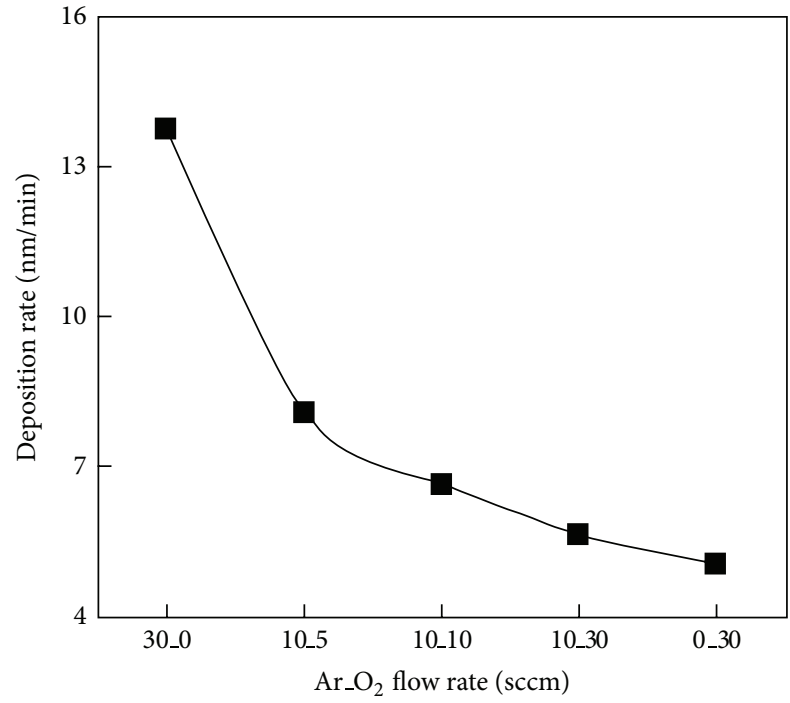

FIGURE 3: The deposition rate comparison for $\mathrm{ZnO}$ films deposited with different working gases.

the uniform and flat surface. Furthermore, it was found that the average grain sizes from different as-deposited $\mathrm{ZnO}$ films were decreased, respectively, from 170, 95, 90, 70 to $60 \mathrm{~nm}$ with the oxygen ratio increasing. According to the result of the deposition rate, it was known that the oxidization effect of the oxygen rich ambient is much strong during deposition, resulting in the formed $\mathrm{ZnO}$ crystalline size in $c$-axis being remarkably increased. In contrast, the average gain size was

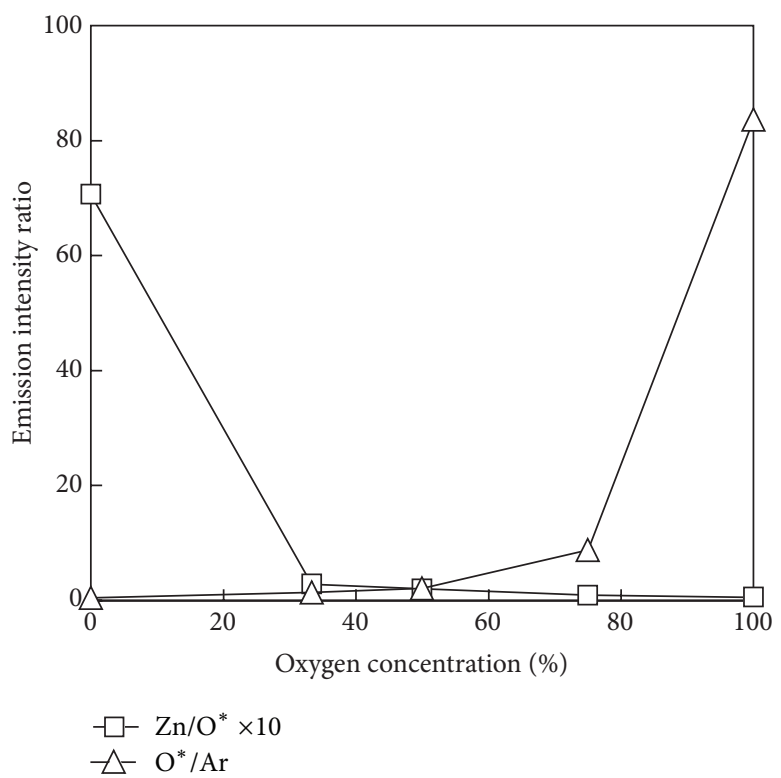

(b)

decreased. Therefore the much flatness surface was obtained from higher oxygen concentration deposition processes.

Figure 5 shows the XRD patterns of the $\mathrm{ZnO}$ thin films deposited from different gas ratio during $\mathrm{rf}$ magnetron sputtering. It was obvious that the (002) diffraction peak was dominated peak which was oriented highly perpendicular to the plane of the substrate for every sample. It was found that the intensity of $c$-axis (002) peak was increased with the oxygen ratio increasing, and the full width at half maximum (FWHM) value of (002) diffraction peaks being correspondingly decreased with the oxygen ratio increasing. In addition, by calculation using the Scherrer formula [12],

$$
D=\frac{K \lambda}{\beta \cos \theta},
$$

where $K$ is the shape factor, $\lambda$ is the $\mathrm{X}$-ray wavelength, $\beta$ is the line broadening at half the maximum intensity (FWHM) in radians, and $\theta$ is the Bragg angle. It was also found that the average crystallite sizes along $c$-axis in the different as-deposited films increased with oxygen ratio increasing, correspondingly as $21,35,36,38$, and $39 \mathrm{~nm}$, as shown in Figure 5(b). Therefore, it was obvious that the crystallinities of the as-deposited $\mathrm{ZnO}$ thin films were significantly improved with the oxygen ratio increasing under high-pressure of $7 \mathrm{~Pa}$ deposition during the rf magnetron sputtering process.

Figure 6 shows the room temperature PL spectra obtained from as-deposited $\mathrm{ZnO}$ films deposited from different working gases $\left(\mathrm{Ar} / \mathrm{O}_{2}\right)$ ambient. It was observed that the strong UV peak centered at $375 \mathrm{~nm}(3.31 \mathrm{eV})$, which is near band edge emission, attributed to excitonic emission due to recombination of photo-generated charge 


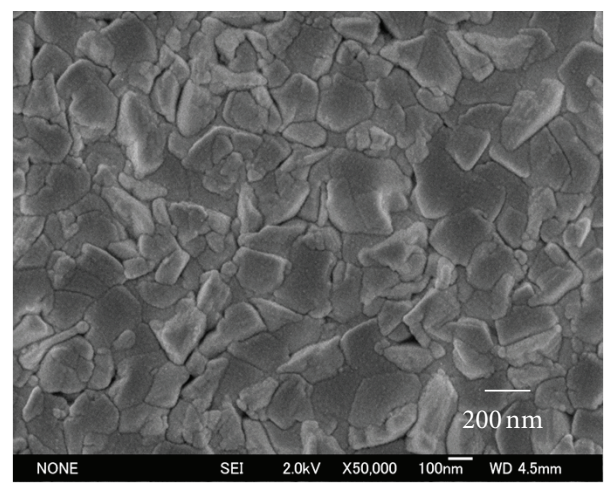

(a)

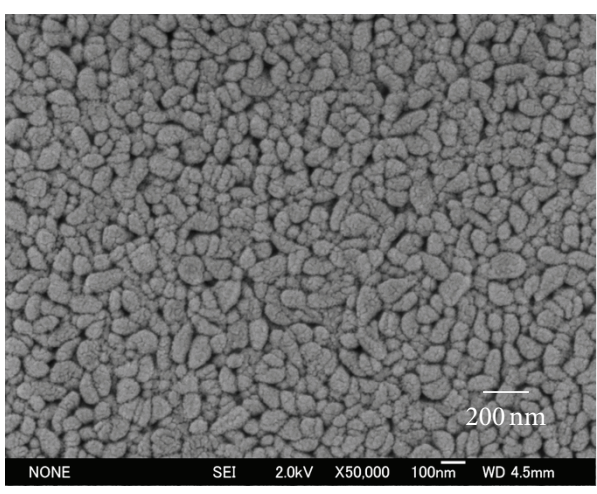

(b)

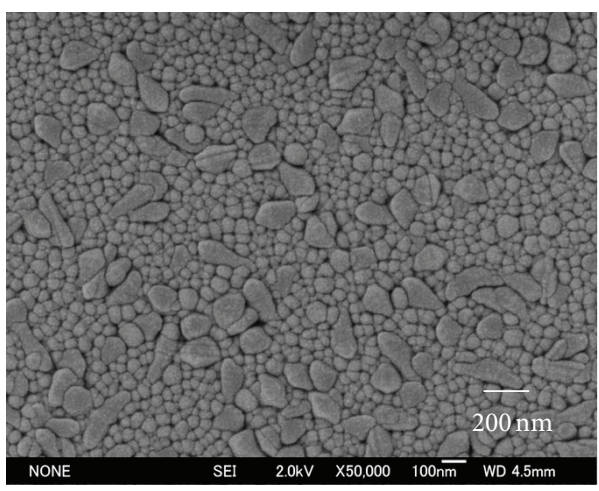

(d)

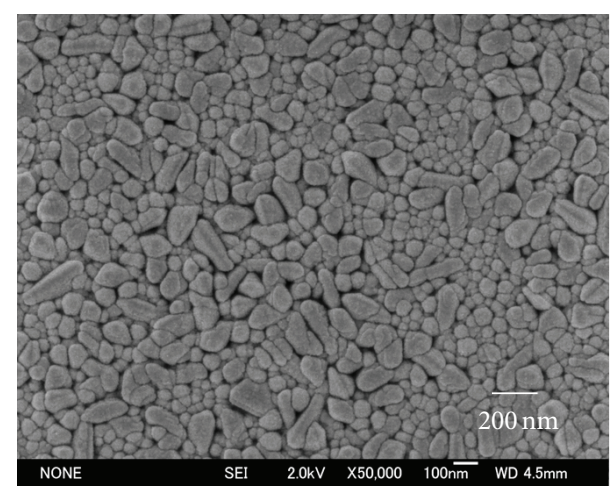

(c)

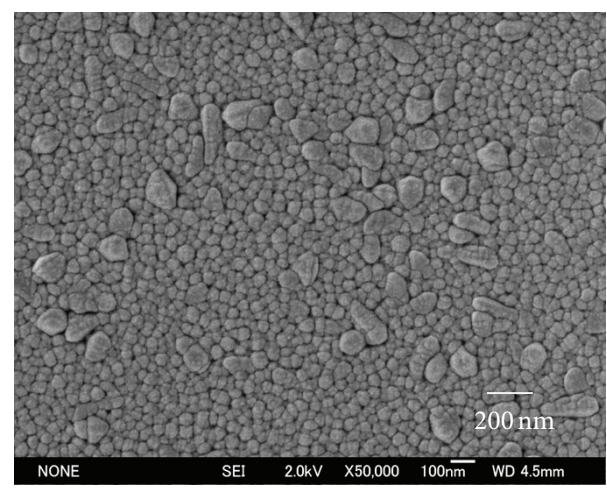

(e)

Figure 4: SEM images of as-deposited $\mathrm{ZnO}$ films obtained under different gas ratios (a) Ar: 30 (sccm), (b) Ar/O $\mathrm{O}_{2}: 10 / 5$ (sccm/sccm), (c) $\mathrm{Ar} / \mathrm{O}_{2}: 10 / 10(\mathrm{sccm} / \mathrm{sccm}),(\mathrm{d}) \mathrm{Ar} / \mathrm{O}_{2}: 10 / 30(\mathrm{sccm} / \mathrm{sccm})$, and (e) $\mathrm{O}_{2}: 30(\mathrm{sccm})$.

carriers dominating the spectrum; meanwhile suppressed deep level emission peaks around 572 604 $\mathrm{nm}$ that covered yellow orange range were also observed from all the samples deposited with the oxygen gas including deposition. It was obviously that the near band edge emission was enhanced with the oxygen ratio decreasing. However, in case of $\mathrm{ZnO}$ film deposited in working gas as pure argon (Ar) ambient, the both strong UV emission peaked at $378 \mathrm{~nm}(3.27 \mathrm{eV})$ with a shoulder about $424 \mathrm{~nm}(2.91 \mathrm{eV})$ and a broad visible emission were observed. According to the calculation for the energy level of various intrinsic defects in $\mathrm{ZnO}$ by applying the full-potential linear muffin-tin orbital method [13], the shoulder peak at $2.91 \mathrm{eV}$ indicated that there was much high ratio of interstitial zinc $\left(\mathrm{Zn}_{\mathrm{i}}\right)$ that existed in the film, which was well consistent with the OES measurement result. It was well accepted that the deep level emission comes from the intrinsic defects in $\mathrm{ZnO}$ film including zinc vacancies $\left(\mathrm{V}_{\mathrm{Zn}}\right)$, oxygen vacancy $\mathrm{V}_{\mathrm{O}}$, interstitial zinc $\left(\mathrm{Zn}_{\mathrm{i}}\right)$, interstitial oxygen $\mathrm{O}_{\mathrm{i}}$, and antisite oxygen $\mathrm{O}_{\mathrm{Zn}}$. It was no doubt that there were many defects introduced to the $\mathrm{ZnO}$ films by sputtering process. From the PL spectra, it was confirmed that the yellow-orange emission (572-604) might be due to excess oxygen during oxygen including sputtering. The film deposited using only argon gas included much more defects 


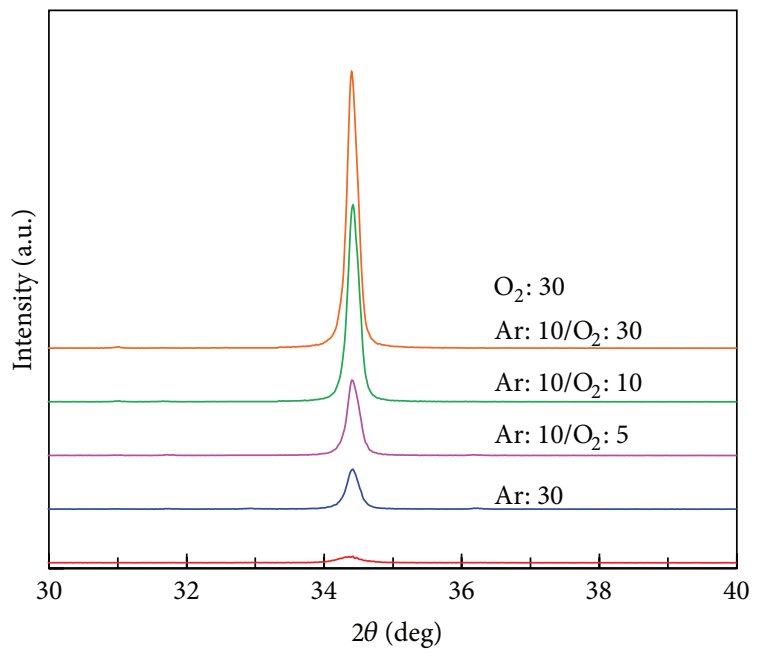

(a)

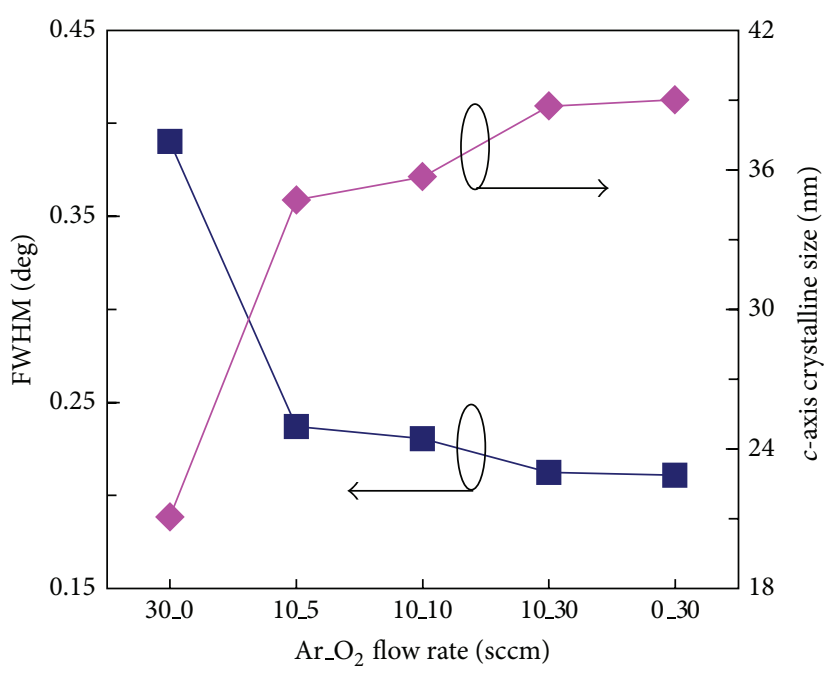

(b)

FIGURE 5: (Color online) (a) XRD patterns of ZnO films, (b) comparison of the FWHM values and c-axis crystalline size in the (002) direction for the films deposited with different $\mathrm{Ar} / \mathrm{O}_{2}$ gas ratios (10/5, 10/10, 10/30 sccm/sccm, Ar and $\mathrm{O}_{2}: 30 \mathrm{sccm}$, resp.).

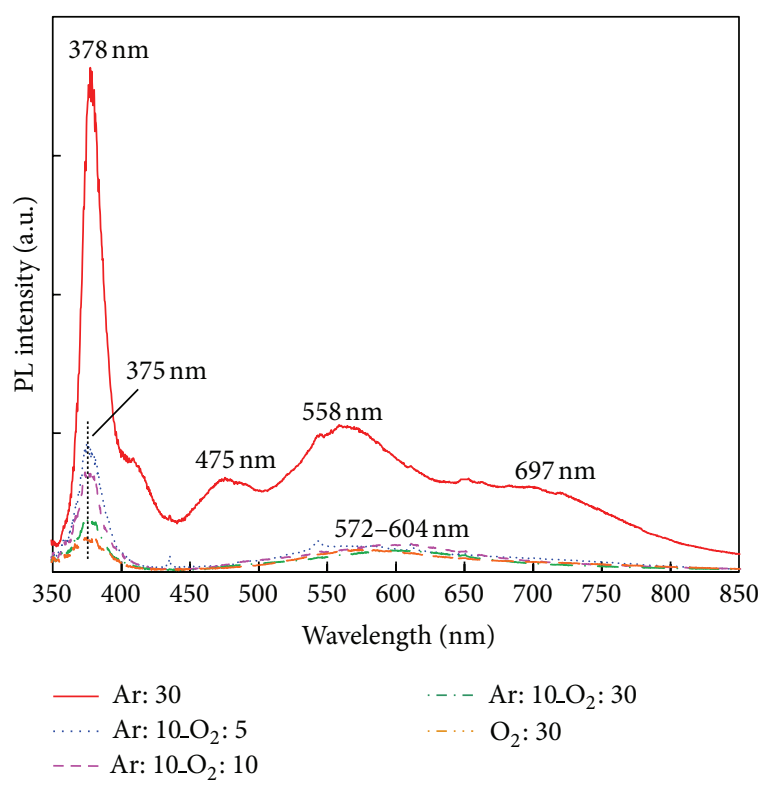

FIGURE 6: (Color online) PL spectra of as-deposited $\mathrm{ZnO}$ films prepared under different working gases ambient at deposition pressure of $7 \mathrm{~Pa}$.

due to lack of oxygen during the $\mathrm{ZnO}$ film deposition; the defects centers in the film need to be further investigated in the further experiment.

\section{Conclusions}

The stoichiometry of $\mathrm{ZnO}$ films deposited at high-pressure of $7 \mathrm{~Pa}$ was significantly dependent on the working gas ambient in $\mathrm{rf}$ magnetron sputtering deposition. The intensity of the excited atomic oxygen $\left(\mathrm{O}^{*}\right)$ during rf plasma sputtering process was increased with the oxygen ratio increasing, resulting in enhancing the $\mathrm{ZnO}$ oxidization during the deposition. It was confirmed by OES measurement that the metal zinc ratio in the $\mathrm{ZnO}$ films was decreased with the oxygen ratio increasing. The crystallinities of $\mathrm{ZnO}$ films were improved with the oxygen ratio increasing. Therefore, it is possible to control the stoichiometry of $\mathrm{ZnO}$ films by simply adjusting the working gas ratio during $r f$ magnetron sputtering process.

\section{Acknowledgment}

The authors gratefully acknowledge the support by Grantin-Aid for Scientific Research (Grant No. 24561060) from the Ministry of Education, Culture, Sports, Science, and Technology, Japan.

\section{References}

[1] R. L. Hoffman, B. J. Norris, and J. F. Wager, "ZnO-based transparent thin-film transistors," Applied Physics Letters, vol. 82, article 733, 3 pages, 2003.

[2] E. M. C. Fortunato, P. M. C. Barquinha, A. C. B. Pimentel et al., "Wide-bandgap high-mobility $\mathrm{ZnO}$ thin-film transistors produced at room temperature," Applied Physics Letters, vol. 85, article 2541, no. 13, 3 pages, 2004.

[3] M. Furuta, T. Hiramatsu, T. Matsuda, C. Li, H. Furuta, and T. Hirao, "Oxygen bombardment effects on average crystallite size of sputter-deposited $\mathrm{ZnO}$ films," Journal of Non-Crystalline Solids, vol. 354, no. 17, pp. 1926-1931, 2008.

[4] T. Shimomura, D. Kim, and M. Nakayama, "Optical properties of high-quality $\mathrm{ZnO}$ thin films grown by a sputtering method," Journal of Luminescence, vol. 112, no. 1, pp. 191-195, 2005.

[5] C. Li, M. Furuta, T. Matsuda, T. Hiramatsu, H. Furuta, and T. Hirao, "RF power and thermal annealing effect on the properties of zinc oxide films prepared by radio frequency 
magnetron sputtering," Research Letters in Materials Science, vol. 2007, Article ID 26459, 5 pages, 2007.

[6] M. Furuta, T. Hiramatsu, T. Matsuda, H. Furuta, and T. Hirao, "Effect of energetic particle bombardment on microstructure of zinc oxide films deposited by RF magnetron sputtering," Japanese Journal of Applied Physics part 1, vol. 46, no. 7A, pp. 4038-4041, 2007.

[7] T. Hiramatsu, M. Furuta, H. Furuta, T. Matsuda, and T. Hirao, "Influence of thermal annealing on microstructures of zinc oxide films deposited by RF magnetron sputtering," Japanese Journal of Applied Physics Part 1, vol. 46, no. 6 A, pp. 3319-3323, 2007.

[8] "Numerical data and functional relationships in science and technology," in Landolt-Börnstein, I Band 1. Teil, S. 87, 88, 200, Springer, New York, NY, USA.

[9] T. Nagata, A. Ashida, N. Fujimura, and T. Ito, "The effects of $\mathrm{Xe}$ on an rf plasma and growth of $\mathrm{ZnO}$ films by rf sputtering," Journal of Applied Physics, vol. 95, no. 8, pp. 3923-3927, 2004.

[10] P. W. B. Pearse and A. G. Gaydon, The Identification of Molecular Spectra, Chapman and Hall, New York, NY, USA, 4th edition, 1984.

[11] K. Tominaga, S. Iwamura, I. Fujita, Y. Shintani, and O. Tada, "Influence of bombardment by energetic atoms on c-axis orientation of zno films," Japanese Journal of Applied Physics Part 1, vol. V21, no. 7, pp. 999-1002, 1982.

[12] M. Birkholz, Thin Film Analysis by X-Ray Scattering, Wiley$\mathrm{VCH}$, Weinheim, Germany.

[13] B. Lin, Z. Fu, and Y. Jia, "Green luminescent center in undoped zinc oxide films deposited on silicon substrates," Applied Physics Letters, vol. 79, article 943, no. 7, 2001. 

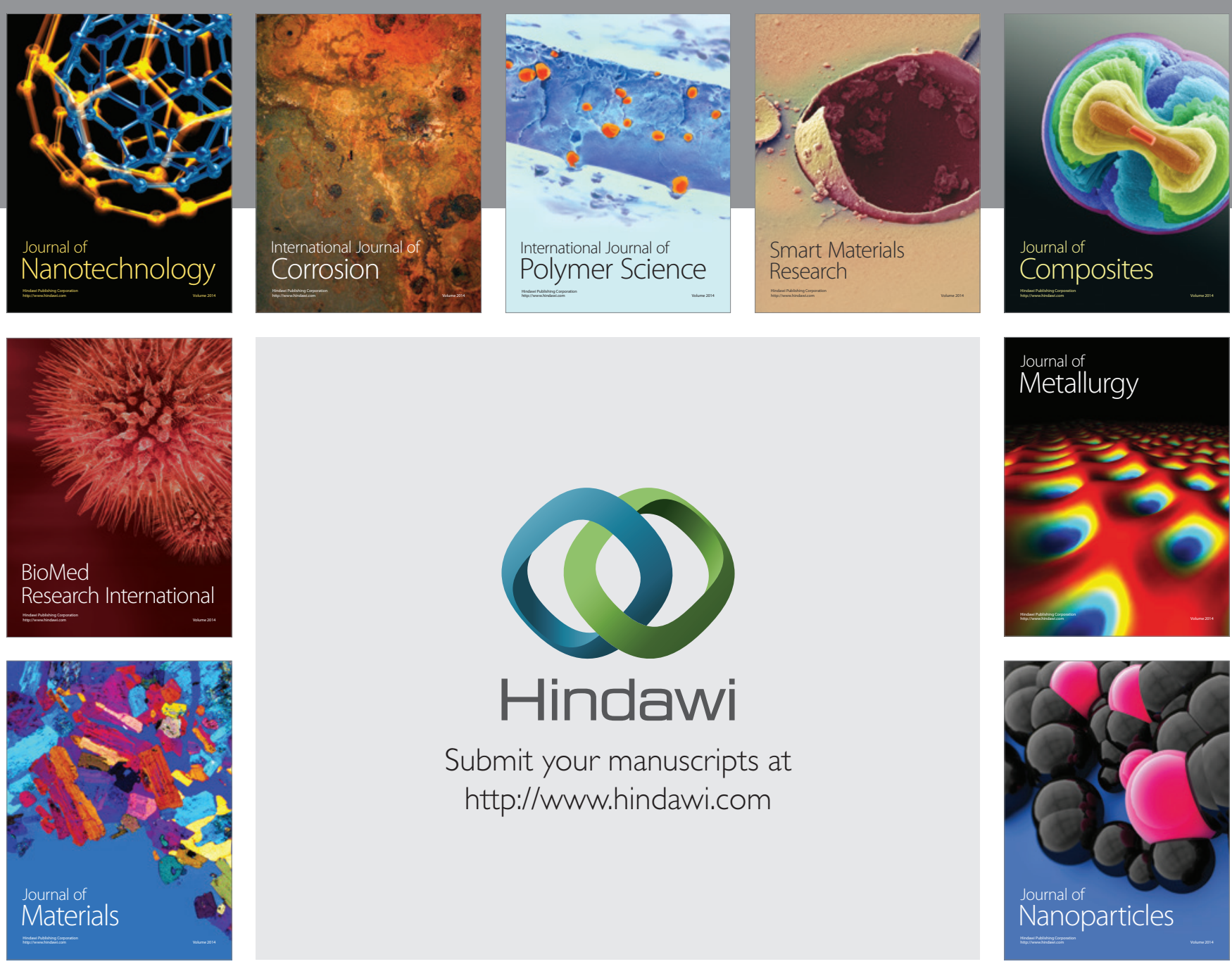

Submit your manuscripts at http://www.hindawi.com
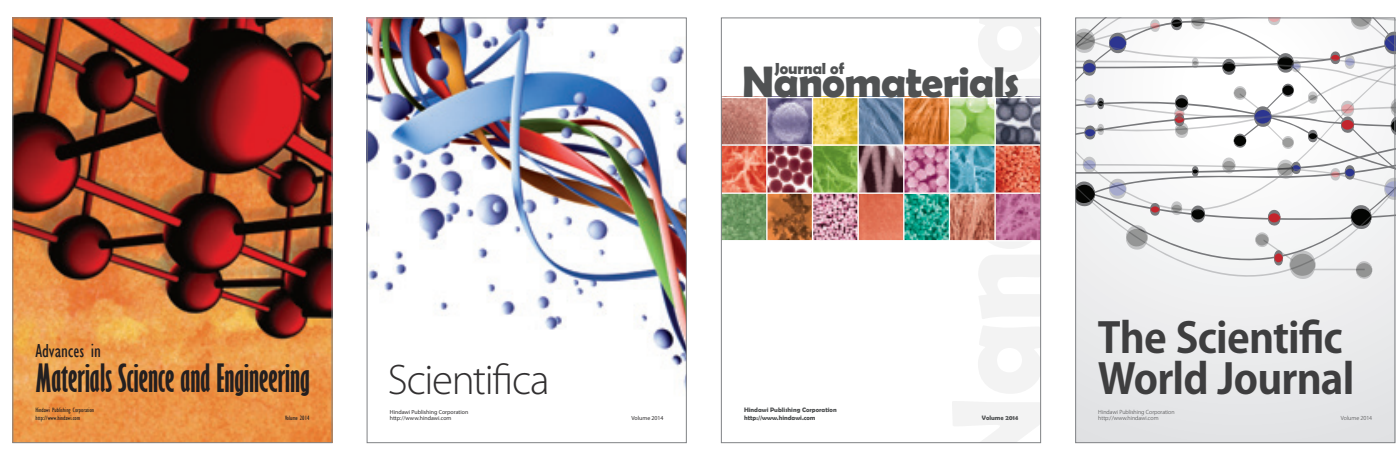

\section{The Scientific World Journal}
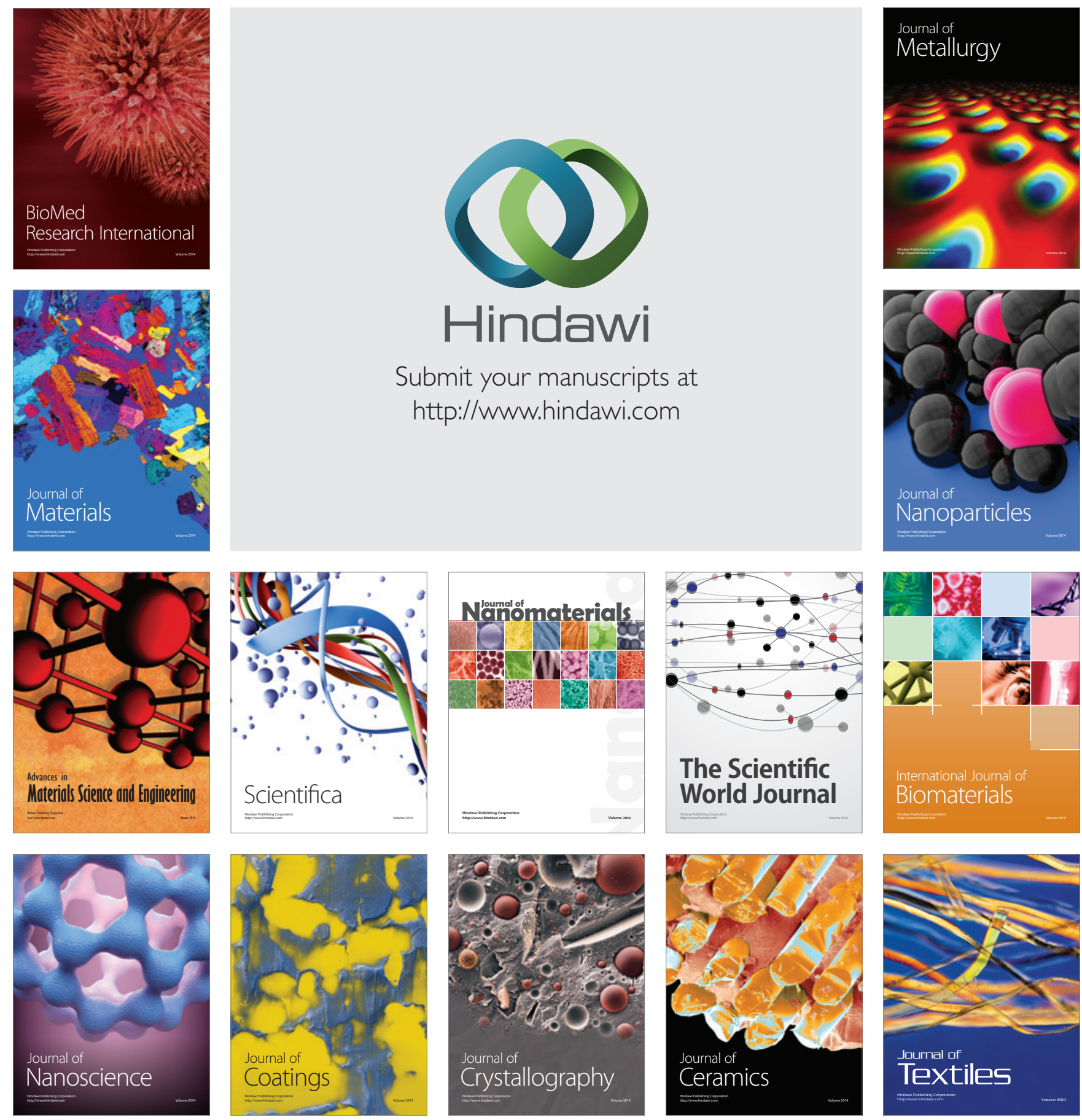